\title{
A multi-criteria decision making approach to the new product development process in industry
}

\author{
Mohamed I. Youssef ${ }^{\mathbf{1}}$, Barry Webster ${ }^{2}$ \\ ${ }^{1}$ Institute of Public Administration, Saudi Arabia, e-mail: youssefm@ipa.edu.sa \\ ${ }^{2}$ Florida Institute of Technology, United States of America, e-mail: bwebster0563@gmail.com
}

\begin{tabular}{l}
\hline \hline Article Info \\
\hline Article history: \\
Received Dec 15, 2021 \\
Revised January 10, 2022 \\
Accepted January 26, 2022 \\
\hline
\end{tabular}

Keywords:

Multi-criteria Decision Making, PROMETHEE Method, New Product Development.

\begin{abstract}
New product development is the process of taking a new idea and turning that idea into an actual product, available on the market. This process includes a number of stages, starting with the product concept and increasingly refining that concept until it becomes the final product and is ready for marketing. The primary function of a Multi-Criteria Decision Making approach is to take the values of a set of criteria and determine an optimal course of action. This research aims to evaluate the significance of using such the PROMETHEE approach to formulate the new product development process within an organization. In order to use that approach to assess the level of improvement that the organization has seen in its performance in new product development, and to estimate the possible level of improvement that might take place if the organization implements suggested recommendations. A research case is studied in order to make this assessment. Results of the case study are presented to demonstrate the feasibility of using a Multi-Criteria Decision Making approach for improving the new product development process within a real-world industrial setting.
\end{abstract}

Copyright (C) 2022 Regional Association for Security and crisis management and European centre for operational research. All rights reserved.

\section{Corresponding Author:}

Mohamed I.Youssef,

Institute of Public Administration, Ibrahim Masaud, As Salamah District, Jeddah 23524 6895, Saudi Arabia. Email: youssefm@ipa.edu.sa

\section{Introduction}

With increased global competition, businesses now face a more complex and dynamic competitive environment and need to develop more innovative products with higher quality and shorter product life cycles. New product development (NPD) is the key to the success of a business. (Yeh , 2013; Klauer, 2006) Engineering managers and project leaders are responsible for getting new product development projects done on time, within budget, and in conformance with customer expectations. They need a tool to match the appropriate engineering methods to projects at the project planning or preliminary stage of development. A firm must be innovative as well as quick to respond to changing customer needs to provide better products to market faster than competitors, thus sustaining competitiveness. (Kumar \& Phrommathed, 2005)

An organization's NPD structure and strategy must be in line with that organization's vision. Organizations that have better control over operating costs have a competitive edge and can provide products or services at lower costs, with higher profit margins. The unrelenting force of global competition is driving industrial organizations to turn their NPD process into a competitive advantage in the marketplace. Many companies have employed individual tools to improve the effectiveness of the NPD process, but few have employed them within the framework of a guiding set of principles or philosophy. This paper attempts to provide such a set of principles, by tying Multi-Criteria Decision Making (MCDM) into the NPD process. This will allow MCDM to function as a guide for the entire NPD process. (Youssef \& Webster, 2013) 
The main objective of this paper is to measure the scientific significance of using an MCDM approach to the NPD process in industry, in order to determine whether MCDM is a viable tool for assisting organizations with improving their NPD process, and if so, to what degree. In addition to the main objective, this paper intends to assess MCDM as an approach for helping decision makers to select the optimal path to be taken to improve an organization's performance in its NPD process.

\section{Literature Review}

\subsection{MCDM Methods}

In today's competitive environment, only rarely can decision problems be resolved by considering a single criterion, attribute, or point of view. Because of this, MCDM emerged as a new branch of decision-making processes. MCDM is based on the idea of taking multiple, often conflicting criteria, each of which is to a greater or lesser extent important to the decision maker, and methodically combining those criteria to produce a recommendation for a course of action. It helps decision makers to select the most adequate decision but not predict the success of that decision. (Asghar \& Habiba, 2009)

There are several subsidiary tools and techniques that can be employed to assist with implementing MCDM: two items in particular, which are related, are Decision Support Systems (DSS) and Multi-Criteria Decision Analysis (MCDA) tools. DSS systems operate using algorithms and models to interpret and analyze information. Several DSSs are available on the market, such as PromCalc, Decision Lab 2000, D-Sight, SmartPicker Pro, and Visual PROMETHEE. MCDA tools involve the use of computer-based systems to enhance the features and quality of decision-making. Both DSSs and MCDAs can be used to assist in the selection of an appropriate course of actions to be taken by the decision maker. In addition to being a set of related computer programs, they incorporate the data required to assist with analysis and decision-making within an organization. (Youssef \& Webster, 2013)

\subsection{Selection of the PROMETHEE Method}

After consideration, the PROMETHEE method was selected as the MCDM method of choice for the case study. The main advantage of PROMETHEE is that it supports group-level decision-making and thus constitutes a useful platform for debate and consensus building. PROMETHEE (as in all outranking methods) can simultaneously deal with qualitative and quantitative criteria. Criteria scores can be expressed in their own units, and PROMETHEE can deal with uncertain and fuzzy information. (Kasperczyk \& Knickel, 2011)

PROMETHEE was chosen for use over the other dominant outranking method, ELECTRE, for several reasons. The PROMETHEE theory and methodology are easier for decision makers to understand. (Klauer, 2006)

PROMETHEE also allows for decision maker involvement at every stage of the decision process. Criteria weights, preference functions, and thresholds can all be manipulated at any point in the process, allowing for a more dynamic interface than ELECTRE (Brans, Vincke, \& Mareschal, 1986) (Pomerol \& Barba-Romero, 2000). In addition, it was found that PROMETHEE rankings to be more stable than ELECTRE rankings. (Brans, Vincke, \& Mareschal, 1986) (Hermans \& Erickson, 2007)

\subsection{Application of Visual PROMETHEE}

A software named "Visual PROMETHEE" was used to develop the model under study. VP is the latest and most complete and up-to-date software implementing the PROMETHEE method, and was developed by Professor Bertrand Mareschal from the Solvay Brussels School of Economics and Management of the Université Libre de Bruxelles (ULB). In the VP implementation, the user needs to define the actions, criteria, scenarios, and model preferences for the decision problem, and organize and weigh the criteria. The software provides users with the required steps to rank different actions, perform a sensitivity analysis, use weight presets, and generate reports. (Mareschal B. , 2013) Figure 1 below shows the Criteria Hierarchy in Visual PROMETHEE. (Youssef \& Webster, 2013) 


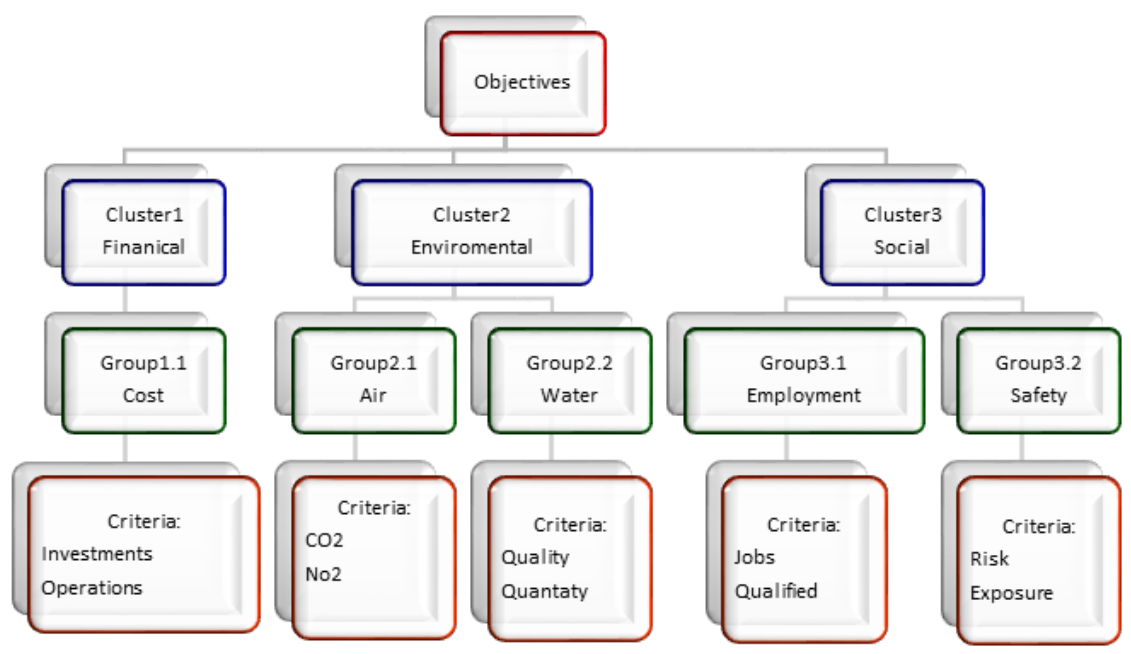

Figure 1. Criteria hierarchy in Visual PROMETHEE

In accordance with (Mareschal B. , 2013), the following introduces a definition for each item used in the VP analysis: Action, Category, Cluster, Coalition, Criterion, Decision maker, Decision problem, Group, Hierarchy, Preference function, Scenario, Weight.

\section{Research Case And Methodology}

The research case used in this study concerns a mid-sized German company (ORGENTEC Diagnostika $\mathrm{Gmbh}$ ) that has been a world market leader in the development, production, and marketing of test systems for laboratory autoimmune diagnostics. The company has a plan to introduce its newest product, a fully automated random access analyzer adopting a new technology, to represent a further milestone in the extremely successful development of its diagnostic systems. (Youssef \& Webster, 2013)

A comprehensive survey questionnaire was developed in an attempt to explore personal tendencies, not organizational tendencies, towards NPD performance. That is, it was designed to reflect the personal opinion of each decision maker towards the applied NPD stages and activities in the past and at the present. To represent the past, a time of seven years prior was chosen, as it marked a reasonable amount of time during which NPD efforts could be conducted, and one at which all current decision makers were involved in the process. Questionnaire respondents were asked to provide prescriptive (normative) marking numbers assigned to represent the applied NPD process. The survey was meant to give a full overview of all NPD process stages and activities, as well as reflect the personal preferences of the decision makers within the company departments towards five main NPD tasks: concept development, market testing \& business analysis, technical implementation, commercialization, and NPD strategies. (Youssef \& Webster, 2013)

The questionnaire consisted of nine sections, totaling 103 multiple-choice and ranking questions, categorized as: General Information (8 questions); MCDM Understanding (11 questions); New Product Development Actions \& Criteria (22 questions); New Product Development Strategy (5 questions); Project Timeliness and Schedules (9 questions); New Product Research (8 questions); Technology Deployment (8 questions); Cost/Profit Margin/Return (13 questions) and Market Turbulence (19 questions). (Youssef \& Webster, 2013)

\subsection{Data and Cluster Aggregation}

The questionnaire responses were aggregated in the data spreadsheet, where each of the respondents' evaluations was represented as two scenarios, one for the company's NPD performance seven years ago and the other for the company's NPD performance at present.

\subsection{Cluster Aggregation}

The first step in the aggregation process was to make each question response from the survey questionnaire fit into specific groups of criteria, and the groups of criteria fit into clusters, as per the VP manual. [9]Table 3 1 shows the clusters that were used. Each cluster represented one of the five main NPD tasks: (1) Concept Development, (2) Market Testing \& Business Analysis, (3) Technical Implementation, (4) Commercialization, and (5) NPD Strategies. A specific shape and color was assigned by the researcher to each cluster for easy 
identification. Each question from the survey questionnaire was then allocated to one of the clusters based on the information captured by that question. Table 1 shows distribution of questions to clusters (Youssef \& Webster, 2013).

Table 1. Distribution of Questions to Clusters

\begin{tabular}{|c|c|c|c|c|c|}
\hline & $\begin{array}{c}\text { Concept } \\
\text { Development }\end{array}$ & $\begin{array}{c}\text { Market Testing \& } \\
\text { Business } \\
\text { Analysis } \\
\text { [ }\end{array}$ & $\begin{array}{l}\text { Technical } \\
\text { Implementat } \\
\text { ion }\end{array}$ & $\begin{array}{l}\text { Commercial } \\
\text { ization }\end{array}$ & NPD Strategies \\
\hline $\begin{array}{l}\text { (C) NPD Actions and } \\
\text { Criteria } \\
\text { (E) Project Timeliness and } \\
\text { Schedules }\end{array}$ & C. 1 to C. 5 & C. 5 to C. 12 & C. 13 to C. 15 & C. 16 to C. 22 & E.1.to E.9 \\
\hline (F) New Product Research & & & & & F.1 to F6 \\
\hline $\begin{array}{c}\text { (G) Technology } \\
\text { Deployment } \\
\text { (H) Cost / Profit Margin / } \\
\text { Return }\end{array}$ & & & $\begin{array}{l}\text { G.1., and } \\
\text { G.4 to G.6 }\end{array}$ & & $\begin{array}{l}\text { G.2, G. } 3, \text { G.7 } \\
\text { and G. } 8 \\
\text { H.1 to H.13 }\end{array}$ \\
\hline (I) Market Turbulence & & & & $\begin{array}{l}\text { I. } 1 \text { to I. } 14, \\
\text { and I. } 16 \text { to }\end{array}$ & I. 15 and I.19 \\
\hline
\end{tabular}

\subsection{Weighting Criteria Clusters}

Survey questions were presented to determine the weighting values of each of the five main NPD tasks, and the respondents were asked to determine the relative importance of each cluster with respect to the others in two different sets of actions, one representing NPD performance seven years ago, and the other representing present performance. An aggregation was made of the values given by the respondents to the five main clusters, as shown in Table 2. (Youssef \& Webster, 2013)

Table 2. Weight of each Cluster as determined by Survey

\begin{tabular}{|c|c|c|c|c|c|c|c|c|c|c|}
\hline \multirow[t]{2}{*}{$\begin{array}{l}\text { Criteria Cluster } \\
\text { (by Color ID) }\end{array}$} & \multicolumn{4}{|c|}{ 口 } & \multicolumn{2}{|c|}{$\bullet$} & \multirow[b]{2}{*}{$\underline{\text { Past }}$} & \multirow[b]{2}{*}{ Pres } & \multirow[b]{2}{*}{$\underline{\text { Past }}$} & \multirow[b]{2}{*}{$\underline{\text { Pres }}$} \\
\hline & $\underline{\text { Past }}$ & $\underline{\text { Pres }}$ & $\underline{\text { Past }}$ & $\underline{\text { Pres }}$ & $\underline{\text { Past }}$ & $\underline{\text { Pres }}$ & & & & \\
\hline $\begin{array}{c}\text { International Sales and } \\
\text { Marketing }\end{array}$ & 5 & 5 & 2 & 2 & 5 & 4 & 4 & 3 & 4 & 4 \\
\hline Marketing & 5 & 5 & 4 & 4 & 3 & 3 & 3 & 3 & 4 & 4 \\
\hline Export & 5 & 5 & 4 & 3 & 3 & 3 & 3 & 3 & 5 & 5 \\
\hline Quality Management & 5 & 5 & 2 & 2 & 4 & 4 & 3 & 3 & $?$ & $?$ \\
\hline Public Relations & 5 & 5 & 2 & 3 & 4 & 5 & 4 & 5 & 4 & 3 \\
\hline $\begin{array}{l}\text { Research and } \\
\text { Development }\end{array}$ & 5 & 5 & 3 & 3 & 4 & 3 & 1 & 0 & 3 & 3 \\
\hline $\begin{array}{l}\text { Production } \\
\text { Management }\end{array}$ & 5 & 5 & 5 & 5 & 3 & 4 & 3 & 3 & 5 & 5 \\
\hline Technical Department & 4 & 5 & 4 & 5 & 5 & 5 & 4 & 4 & 5 & 4 \\
\hline Top Management & 4 & 4 & 2 & 2 & 3 & 3 & 4 & 4 & 4 & 5 \\
\hline $\begin{array}{c}\text { Quality Control } \\
\text { Department }\end{array}$ & 5 & 5 & 4 & 4 & 4 & 2 & 5 & 2 & 3 & 3 \\
\hline Average & 5 & 5 & 3 & 3 & 4 & 4 & 3 & 3 & 4 & 4 \\
\hline
\end{tabular}

The last row of Table 2 shows the average of the decision maker's evaluations for the importance of each cluster in comparison to the others, which was used as the weighted value for each cluster in the VP model analysis (Youssef \& Webster, 2013).

\subsection{Ranking Criteria Clusters}

The respondents' answers in the survey questionnaire constituted a comparison between the clusters, in order to identify the overall priorities of the five main tasks (clusters) in the NPD performance. This was done 
in order to get to the values of how substitutable or complementary the criteria involved in the NPD process are in the mind of the decision makers. (Youssef \& Webster, 2013)

\section{Visual PROMTHEE Model Implementation}

VP requires the modeler to associate a preference function type with each criterion in order to model the manner in which the decision maker perceives the measurement scale of that criterion. There are six different preference function types available in VP; the four most common are [9]:

- $\quad$ Type I (the "Usual" type) is used primarily for qualitative criteria that include a small number of evaluation levels (e.g. a qualitative five-point scale ranging from "very bad" to "very good").

- Type IV (the "Level" type) is primarily used for qualitative criteria with a larger number of evaluation levels.

- Type V (the "Linear" type) and Type III (the "V-shape" type, a special case of type V), are primarily used for most quantitative criteria.

Type III was chosen for the VP model for the research case, as it is a function type well suited to quantitative criteria where even small deviations are accounted for, which is descriptive of the data collected from the survey. (Youssef \& Webster, 2013)

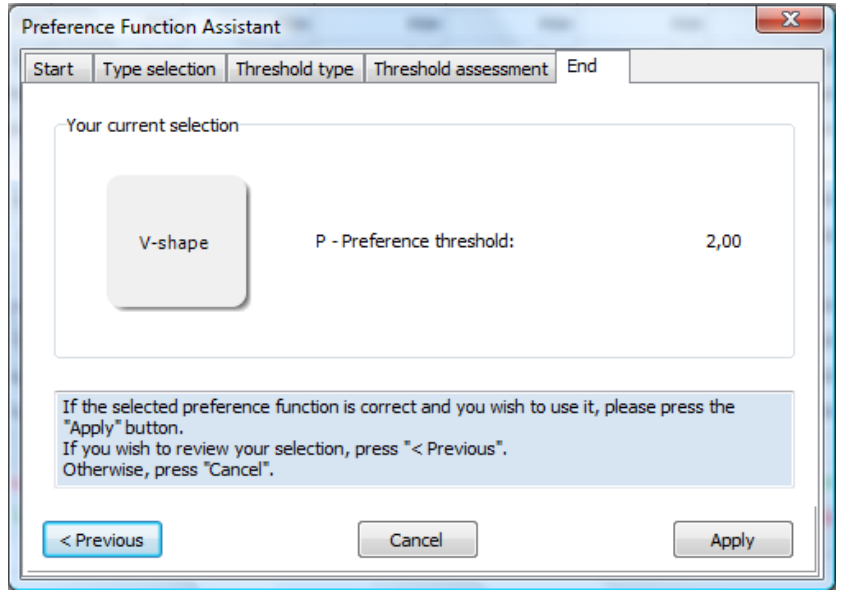

Figure 2. The preference function assistant from VP

Depending on the type of preference function selected, up to three thresholds must be assessed. These are: (1) Q - the indifference threshold, (2) P - the preference threshold, and (3) S - the Gaussian threshold. The Q threshold represents the largest deviation that is considered negligible by the decision maker. The $\mathrm{P}$ threshold represents the smallest deviation that is considered sufficient to generate a full preference. The $\mathrm{S}$ threshold corresponds to the inflection point of the Gaussian curve for the preference function, and thus represents a deviation for which the degree of preference is equal to 0.39 . This threshold is generally the most difficult to assess. Figure 2 shows a screenshot of the Preference Function Assistant from the VP software, where the preference function type is selected and the thresholds defined. (Youssef \& Webster, 2013)

\subsection{Weighting the Criteria}

Weights represent the relative importance of the various criteria. Typically they are non-negative numbers, independent of the measurement units of the criteria, with the idea that the greater the value of the weight, the more important the criterion is considered by the decision maker. Weights are often normalized, such that:

$$
\sum_{j=1}^{k} w_{j}=1
$$

As mentioned previously, this method of weighting does have some limitations. However, it is also very familiar and widely used. As a result, methods such as the preference function have been developed to help 
deal with these limitations. The use of normalized weighting factors along with a preference function is the approach that VP takes.

Respondents determined the relative importance of each of these tasks with respect to the others, both for the past (seven years prior) and the present. These values were then averaged to obtain the weights used within the VP model. The data for this process were shown in Table 2.

In the VP software, the modeler is allowed to select and enter real numbers to be used for the weights of the input criteria. These numbers are then automatically divided by the sum across all criteria, thus normalizing the weights, as shown in Figure 3 (Youssef \& Webster, 2013).

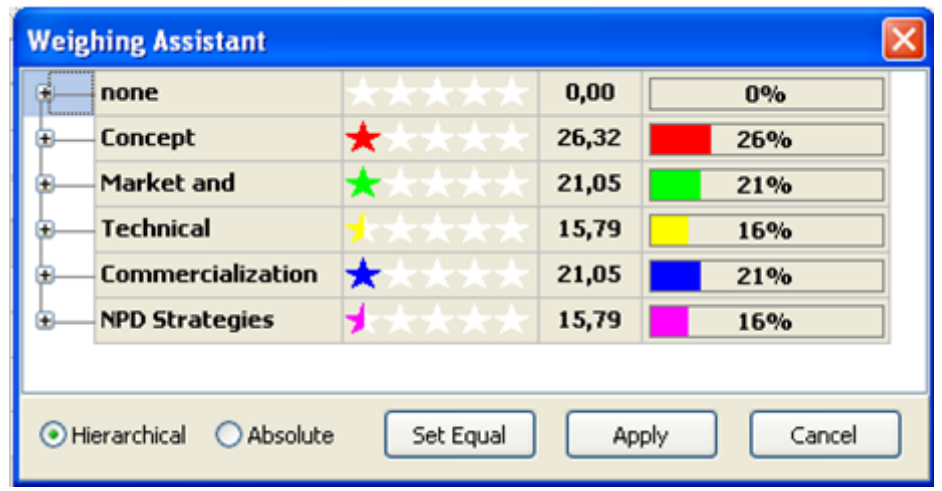

Figure 3. VP normalized weights

Assessing weights for criteria involves the personal preferences of the decision maker, and as such can be a very complicated process. (Brans \& Mareschal, 2005)

\subsection{VP Solution Rankings}

The PROMETHEE method is based on pairwise comparisons, aggregated preference indices, and outranking flows. (Mareschal \& Brans, 1991) To illustrate, let:

$$
\pi(a, b)=\sum_{j=1}^{k} P_{j}(a, b) w_{j}
$$

Where $(a, b) \in A$, the set of all actions (alternatives), $\pi(a, b)$ is a measurement of how much a is preferred to $b$, taking into account all the criteria, their preference indices, and their weights. $\mathrm{k}$ is the number of criteria, $\mathrm{Pj}(\mathrm{a}, \mathrm{b})$ is the preference index comparing $\mathrm{a}$ and $\mathrm{b}$ on criterion $\mathrm{j}$. wj is the weighting factor for criterion $\mathrm{j}$.

\subsection{Preference Flows}

According to (Mareschal B. , 2013), preference flows are constructed to aggregate the pairwise comparisons of actions, and then rank all the actions from best to worst. There are three different preference flows that need to be computed: (1) Phi $+(\Phi+)$ - the positive (or leaving) flow, (2) Phi- $(\Phi-)$ - the negative (or entering) flow, and (3) Phi $(\Phi)$ - the net flow. The positive preference flow $\Phi+$ (a) calculation (shown below) measures how much an action (a) is preferred to the other $n-1$ (out of a set of $n$ possible actions). It is a measure of the overall strength of action a, meaning the larger the value of $\Phi+$, the better the action.

$$
\phi^{+}(a)=\frac{1}{n-1} \sum_{b \neq a}^{n} \pi(a, b)
$$

The negative preference flow $\Phi$-(a) calculation (shown below) measures how much the other n-1 actions are preferred to action a. It is a measure of the overall weakness of action a, meaning the smaller the value of $\Phi$-, the better the action.

$\Phi^{-}(a)=\frac{1}{n-1} \sum_{b \neq a}^{n} \pi(b, a)$ 
The net preference flow $\Phi$ (a) calculation (shown below) is simply the difference between the positive and negative preference flows. It thus takes into account and aggregates both the relative strength and weakness of an action into a single score. $\Phi$ (a) can be positive or negative, and the larger the value, the better the action.

$$
\Phi(a)=\Phi^{+}(a)-\Phi^{-}(a)
$$

\subsection{PROMETHEE II Complete Ranking}

The PROMETHEE II ranking is a complete ranking, meaning that the ranking is based on the net preference flow $(\Phi)$. Consequently, the ranking will not show any incomparable relationships between actions. This renders the resulting ranking more questionable, especially when there are situations in which some preference indices favor one action and some favor another.

Since the ranking is based on the net preference flow $(\Phi)$, it combines the other two preference flows into a single summary score. So, action a is preferred to action $b$ in the PROMETHEE II complete ranking if and only if a has a higher $\Phi$ score.

\section{Results Analysis}

The results obtained from the VP model developed by entering the data from the survey questionnaire regarding the criteria, criteria weights, criteria clusters, and cluster rankings into the VP software. These results were then used to indicate whether there has been an improvement in the research case company's NPD process over the past seven years. Additionally, an attempt was made to predict the company's future NPD process performance by using the data from the survey questionnaire relating to the company NPD associates' views on how the NPD process should operate going forward. (Youssef \& Webster, 2013)

\subsection{VP Analysis of Past and Present NPD Process Performance}

The results of this analysis indicate that the company's NPD performance has significantly improved over the past seven years. The lines for the "Present" and "7 years ago" actions never intersect, meaning that the "Present" action is preferred. Figure 4 shows the VP complete ranking. We should note that even though the VP complete ranking represents the company's past performance with a negative value (-0.0698) and the company's present performance with a positive value (0.0698), this does not imply that the company's performance in the past was poor or below a standard level. The " 0.0 " mark on the diagram does not represent a standard level; it simply represents the position where the $\Phi$ value equals 0 . If there are only two actions, then by the definitions of the preference flows, the $\Phi$ value will be positive for one action and negative for the other, unless the two actions are indifferent (in which case $\Phi$ value for both actions will be zero. (Youssef $\&$ Webster, 2013) 


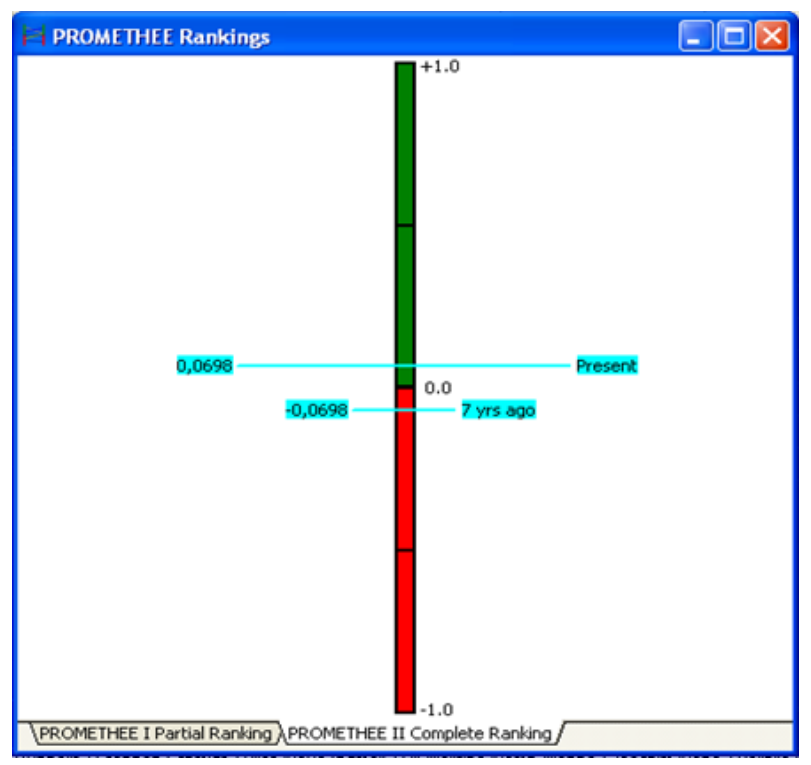

Figure 4. VP Complete ranking of past vs. present NPD Performance

\subsection{Evaluation of Future Performance Values}

Missing values can arise in a multi-criteria model for various reasons. There could be a lack of access to data, a criterion could be pertinent for only some actions, or the information may simply be unavailable for some actions. This problem can be addressed in different ways. (Youssef \& Webster, 2013)

As most MCDA methods rely on the availability of all the evaluations in the multi-criteria model, the generally used approach is to fill in the missing values with replacement values. These replacement values can be: (1) a fixed value, such as zero. This is obviously completely arbitrary and can introduce unwanted biases in the analysis. For instance, replacing a missing cost value with zero dollars is very dangerous. (2) A missing value can be computed from the distribution of the available evaluations on the corresponding criterion (e.g. the arithmetic average). This will reduce the biases, but it is still arbitrary to assume that the missing value is centralized. (3) The missing value can be estimated, provided that an appropriate procedure is available to do so. (Mareschal \& Brans, 1991)

Accordingly, those data points representing the projected future NPD performance of the company were effectively "missing values" as far as the data were concerned. As such, a method had to be chosen to "replace" those data points in order to provide the projections for future performance. The choice was made to estimate the data points, not as an arithmetic average but according to the following steps: first, a change rate factor was calculated by using the preference difference given by each respondent to differentiate between the company's NPD performance seven years ago and at the present. The values presented by the decision maker for the present performance were divided by the values presented by the decision maker for the NPD performance seven years ago. This gave, on a per-person basis, the relative increase or decrease in importance of criteria clusters for each decision maker between seven years ago and at present. The calculated change rate factors are given in Error! Reference source not found.. (Youssef \& Webster, 2013) 
Table 3. Change rate factors for each Cluster

\begin{tabular}{cccccc}
\hline Criteria Cluster (by Color ID) & & $\boldsymbol{\nabla}$ & & $\square$ & 0 \\
\hline (MENA) Regional Manager & 1 & 1 & 1.25 & 1.33 & 1 \\
Director of Infectious Disease & 1 & 1 & 1 & 1 & 1 \\
Director of International sales & 1 & 1.33 & 1 & 1 & 1 \\
Quality Management Representative & 1 & 1 & 1 & 1 & 1 \\
Public Relations Department Head & 1 & 0.66 & 0.8 & 0.8 & 1.33 \\
Head of Research \& Development & 1 & 1 & 1.33 & 0 & 1 \\
Head of Production & 1 & 1 & 1.25 & 1 & 1 \\
Technical Applications Manager & 0.8 & 0.8 & 1 & 1 & 1.25 \\
Managing Director & 1 & 1 & 1 & 1 & 0.8 \\
Quality Control Manager & 1 & 1 & 2 & 2.5 & 1 \\
\hline
\end{tabular}

Second, the change rate factor was multiplied by the present value of each criterion, the result being an extrapolation of the criteria values to be used in the future scenario of the VP analysis. Finally, each criteria cluster was weighted according to the rankings given by the respondents, as was shown in Table 32 . This represents the relative proportion of resources that each respondent feels should be allocated to each of the five main NPD tasks moving forward into the future. Together, the adjusted criteria values and the criteria cluster rankings provide an indication of what might happen if the research case company follows its intended direction for their NPD process. (Youssef \& Webster, 2013)

\subsection{VP Analysis of Past, Present, and Future NPD}

The results of this analysis show that the presence of the third scenario affected the relative ranking between the other two scenarios. It shows that there is a deviation in the path of the line representing the company's present NPD performance. The overall result reflects that if the company follows the recommendations of its NPD associates to emphasize certain NPD strategies and stages (criteria), they could expect a continued improvement in their future NPD efforts. The complete ranking of these same three scenarios is given in Figure 5. (Youssef \& Webster, 2013)

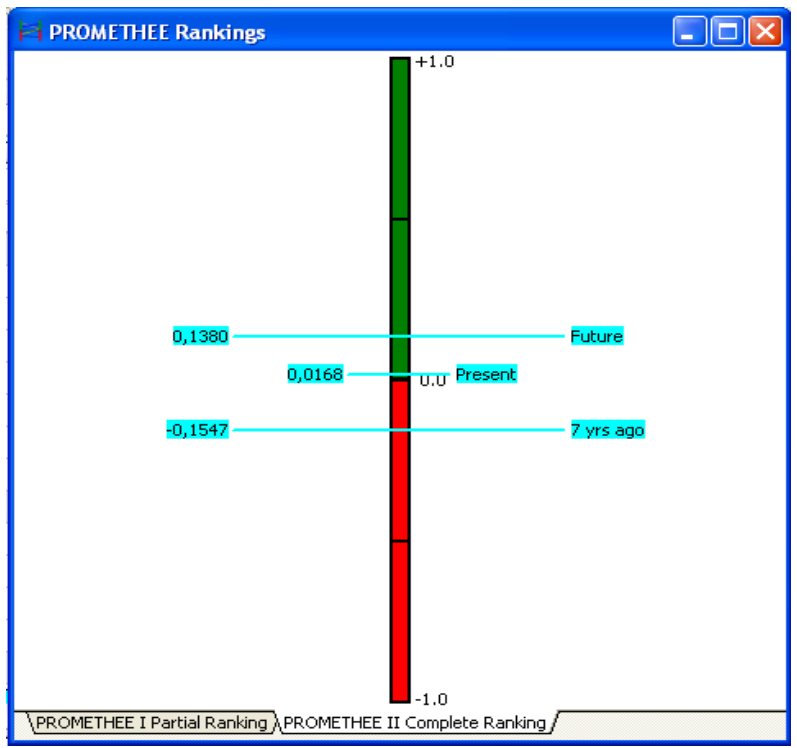

Figure 5. Complete ranking of past vs. present vs. projected Future NPD Performance 
In the VP complete ranking we can easily notice that the positioning of the value representing the company's present NPD performance is still positive, but its value has changed from (0.0698) to (0.0168), while the company's past NPD performance has changed from $(-0.0698)$ to $(-0.1547)$. The rank of the values representing the company's projected future NPD performance takes the highest position (0.1380). Again, these values just represent the relative $\Phi$ values of the three alternative actions, and do not reflect good or poor performance (Youssef \& Webster, 2013).

\section{Conclusion}

The conclusions of this research can be summarized as follows: The knowledge and experience of the NPD associates at the research case company regarding MCDM methods are limited. None of the NPD associates at the company has yet implemented a DSS of any kind to be used in the evaluation of NPD criteria and scenarios; thus, there is a significant need to use an assessment tool at the company to judge and evaluate the different NPD criteria and scenarios. The VP model was designed to provide features to generate optimal scenarios, and it did so, but it failed to predict future outcomes; it could support estimation of missing values for one criterion or more, but not a full scenario. As a result of these missing features, a different tool and/or secondary approach is necessary to provide these capabilities. In spite of its limitations, the MCDM approach proved to be very effective in organizing the decision problem in the minds of the decision makers; it forced them to closely examine their NPD process and its elements, and to think through what was really important in that process. Whether or not the method used for predicting future results proves to be accurate, the results of the analysis provided valuable input to the company going forward with improving their NPD process. (Youssef \& Webster, 2013)

Acknowledgement: The paper is a part of the research done within a master's thesis conducted at the Engineering Systems department in the Florida Institute of Technology. The authors would like to thank ORGENTEC Diagnostika GmbH for their assistance with collection of the data and for allowing the opportunity to conduct this research in cooperation with them. Special thanks is extended to the staff of this company who took their time to respond to the research questionnaire.

\section{References}

Asghar, S., \& Habiba, U. (2009). A Survey on Multi-Criteria Decision Making Approaches. International Conference on Emerging Technologies (pp. 321-325). Islamabad: IEEE.

Brans, J. P., \& Mareschal, B. (2005). PROMETHEE Methods. In J. P. Brans, \& B. Mareschal, Multiple Criteria Decision Analysis: State of the Art Surveys (pp. 163-186). New York: Springer Science + Business Media, Inc.

Brans, J. P., Vincke, P., \& Mareschal, B. (1986). How to Select and How to Rank Projects: The PROMETHEE Method. European Journal of Operational Research, 228-238.

Hermans, C. M., \& Erickson, J. D. (2007). Multicriteria Decision Analysis: Overview and Implications for Environmental Decision Making. Advances in the Economics of Environmental Resources, Vol. 7, 213-228.

Kasperczyk, N., \& Knickel, K. (2011, September 29). Preference Ranking Organisation Method for Enrichment Evaluations (PROMETHEE). Journal of Environmental Assessment Policy and Management, Vol. 09, 1-6.

Klauer, e. (2006). Multicriteria Analysis Under Uncertainty with IANUS - Method and Empirical Results. Environment and Planning C: Government and Policy, Vol. 24, 235-256.

Kumar, S., \& Phrommathed, P. (2005). New Product Development, An Empirical Study of the Effects of Innovation Strategy, Organization Learning, and Market Conditions. Minneapolis: Springer Science+Business Media, Inc.

Mareschal, B. (2013). Visual PROMETHEE 1.3 Manual. Brussels: B. Mareschal.

Mareschal, B., \& Brans, J. P. (1991). Bank Adviser. An Industrial Evaluation System. European Journal of Operational Research, 54, 318-324. 
Pomerol, J.-C., \& Barba-Romero, S. (2000). Multicriterion Decision in Management - Principles and Practice. Norwell: Kluwer Academic Publishers.

Yeh , e. (2013). Using a Hybrid MCDM Methodology to Identify Critical Factors in New Product Development. Neural Computing and Applications, 2013, 1-15.

Youssef, M. I., \& Webster, B. (2013). A Multi-Criteria Decision Making Approach to the New Product Development Process in Industry. Melbourne: Florida Institute of Technology. 